\title{
The Epidemiology of Alcohol use Disorder in the Covid-19 Pandemic: A Kenyan Perspective
}

\author{
George Njoroge ${ }^{1}$, Prof Catherine Mwenda ${ }^{2}$, Dr. Ezekiel Mecha ${ }^{3}$, Dr. Stanley Waithaka ${ }^{1}$ \\ Samuel Mungai ${ }^{1}$ \\ ${ }^{1}$ College of Health Sciences, Mount Kenya University \\ ${ }^{2}$ School of Nursing Sciences and Public Health, South Eastern Kenya University \\ ${ }^{3}$ Department of Biochemistry, University of Nairobi
}

Kenya

\begin{abstract}
1.ABSTRACT
Aims: During the covid-19 pandemic period restrictions on alcohol consumption have been imposed by various governments guided by World Health Organization Coronavirus disease (Covid-19) guidelines on public protection. The focus is to limit the spread of Coronavirus disease. The study aims at using an Alcohol Use Disorder Identification Test as a screening tool to explore experiences of alcohol consumption during the past one year of the Covid-19 pandemic among adults under rehabilitations in Kenyans.
\end{abstract}

Methods: Descriptive cross sectional quantitative research design was used. Participants were sort from two Counties in Kenya with the highest rate of alcohol use while purposive sampling method was used to select two rehabilitation facilities with the highest number of admitted clients. Ninety three respondents participated; this was $83 \%$ of the calculated sample size.

Results: Study results tested hazardous alcohol use found that on the sequence of alcohol consumption, $71 \%$ of the participants consumed alcohol 4 or more times in a week. The test on dependence alcohol use found that on daily or almost daily most of the participants were unable to stop drinking once started, were unable to meet expectations due to drinking and needed a first drink in the morning after a heavy session, they were represented by $51.6 \%, 51.6 \%$ and $66.7 \%$ respectively. On harmful alcohol use $82 \%$ of the participants were concerned to cut down on their drinking.

Conclusion: Alcohol Use Disorder Identification Test is an important tool to evaluate alcohol consumption during the covid-19 restrictions.

Key words: Alcohol drink, County, Drinking, Covid-19 pandemic.

\section{INTRODUCTION}

Alcohol is the most consumed substance in the world with an estimate of over 4 billion persons believed to be alcohol consumers while among them 76.3 million persons suffer from alcohol use disorder ${ }^{1}$. In a study on global alcohol exposure, it was reported that prevalence of drinking alcohol increased from $45 \%$ in 1990 to $47 \%$ in 2017 with a forecast of increasing to $50 \%$ by $2030^{2}$. The United Nation (UN) General Assembly in 2015 adopted the " Transforming Our World: The 2030 Agenda for sustainable development" resolution. Among the targets was Sustainable Development Goals (SDG) with goal number 3 focused on strengthening the prevention and treatment of substance abuse which include narcotics and harmful use of alcohol ${ }^{3}$.

In 2013 the World Health Assembly adopted the WHO Global Action plan to reduce morbidity and mortality due to Non communicable diseases by the year 2025 . It was postulated that mortality due to harmful alcohol use could be reduced by $10 \% 4$. Governments and non-governmental organizations were required to formulate modalities to achieve the targets. Among them was; 
to set national Non Communicable Diseases targets for 2025, development of multisectoral exposure reduction strategies on the risk factors by 2025 and to measure the outcome results of the action plan ${ }^{4}$.

The World Health Organization reported that in the year 2016, over 1.7 million persons died of harmful alcohol use, this represented $5.3 \%$ of all death globally ${ }^{5}$. The pattern of alcohol drinking in the world shows that by 2016 heavy episodic drinking was high (60 grams in a single occasion) with the sub-Saharan Countries showing a range of between $45 \%$ to $60 \%{ }^{5}$. Due to unavailability of actual data the prevalence of alcohol disorder may not be well known in some low income Countries. There are treatment gaps in interventions on alcohol use disorders and especially in low income and middle income Countries. A lot of development need to be put in place to close the gap and more so in the health care facilities ${ }^{6}$. Individuals and collective efforts will be important to salvage the already diseased persons while preventing more new cases of Alcoholic Liver Injury (ALI).

A study involving various low income and middle income Countries found that $16.4 \%$ of the participants had alcohol use disorder with projection for ALI. It is estimated that low-income and middle-income Countries have about 97\% treatment gap for ALI due to alcohol use disorders ${ }^{8}$. The Alcohol Use Disorder Identification Test (AUDIT) screening tool was developed to identify excessive alcohol use that could be a possible cause of medical conditions ${ }^{9}$. After identification of the disease early intervention to prevent further disease development is recommended ${ }^{1}$.

The AUDIT screening tool was intended to identify persons with alcohol use disorder, then for those with hazardous alcohol use the health care workers were to offer brief advice, for dependence use, they were to offer counselling and further evaluation while for harmful use, the health care workers were to offer diagnostic and referral services ${ }^{8}$. The AUDIT tool has three domains represented by the hazardous alcohol use domain, the dependence use domain and the harmful alcohol use domain. Originally the WHO adopted a standard drink as $10 \mathrm{~g}$ of alcohol content but other studies done have encouraged that a standard drink be $14 \mathrm{~g}$, this study adopted a standard drink as $14 \mathrm{~g}$ alcohol content in a drink ${ }^{1,10,11,12}$.

The Alcohol Use Identification Test (AUDIT) during the Covid-19 pandemic aimed at identifying how participants would adapt to the pandemic and adhere to the restrictions despite the alcohol consumption behavior. Persons of hazardous drinking are likely to continue alcohol consumption despite the changes of phenomenon, places or durations of the year ${ }^{13}$. They will continue drinking since hazardous drinking is not life threatening and as such majority do not find it necessary to stop drinking at this level 12

In japan, $9.5 \%$ of the participants were moderate drinkers, 3.6\% were heavy drinkers while $41.6 \%$ were binge drinkers (consume about 5 drinks in 2 hours). Moderate drinking is unsafe and is considered an important factor for prevention of Alcohol Use Disorder (AUD) ${ }^{14}$. An AUDIT study found that $14.7 \%$ of participants were dependence consumers while $52.5 \%$ of the participants were having harmful alcohol use. In a study in Tamil Nadu, AUDIT established that 67\% of the reporters had problematic alcohol drinking patterns, $52 \%$ of the total participants had hazardous or harmful drinking pattern while $14 \%$ had dependence symptoms ${ }^{15}$. A study in Ethiopia assessed alcohol use disorder using the AUDIT tool and found that $34.5 \%$ of the participants had prevalence of the disorder ${ }^{16}$. About $76.2 \%$ of Kenyans have ever used alcohol with $49.9 \%$ having harmful alcohol use $^{17}$.

\section{METHODOLOGY}

This was a descriptive cross sectional study which involved 93 participants from two Counties (Regions) in Kenya. The target population was adults living in the selected Counties. Participants were recruited in rehabilitation Centres, purposive sampling ws used to select the two regions based on the highest number of admitted patients/clients. Those included in the study were required to consent and above the age of 18 years (adults as per the Country's constitution definition of the lower legal age limit). The study excluded persons who were diagnosed with other psychiatric disorders and could not provide reliable information. For reliability of the results, they were subjected to Cronbach's alpha test. Data was collected using a structured questionnaire (AUDIT tool) which was administered by trained nurses. Data was cleaned and entered on Statistical Package for Social Science (SPSS) version 23. Ethical considerations were sort from the Institutional Ethical Review Committee of Mount Kenya University (approval number 865) and the National Commission for science Technology and innovation (NACOSTI) (NACOSTI/P/21/10477). Confidentiality was maintained in the study and patient identifiers were collected in the data. The questionnaires were coded with unique codes for each participant.

\section{FINDING AND RESULTS}

Ninety three respondents were involved in the study, this represented 83\% of the calculated sample size of 108. Majority (40.9\%) of the participants were between the age of 28 and 37 years. Male were more than female at $95.7 \%$ while those married were 
$44.1 \%$ and single participants were $33.3 \%$. Regarding education level, secondary school was at $58.1 \%$ while those with a monthly income of US\$ 1 to 500 were at $36.6 \%$. (Table 1)

Table 1: Bio-demographic data

\begin{tabular}{|c|c|c|c|}
\hline Test Item & & $\mathbf{N}$ & $\%$ \\
\hline \multirow[t]{5}{*}{ Age in years } & $18-27$ & 17 & $18.3 \%$ \\
\hline & $28-37$ & 38 & $40.9 \%$ \\
\hline & $38-47$ & 27 & $29.0 \%$ \\
\hline & $48-57$ & 6 & $6.5 \%$ \\
\hline & ABOVE 58 & 5 & $5.4 \%$ \\
\hline \multirow[t]{3}{*}{ Gender } & Male & 89 & $95.7 \%$ \\
\hline & Female & 4 & $4.3 \%$ \\
\hline & Transgender & 0 & $0.0 \%$ \\
\hline \multirow[t]{5}{*}{ Marital status } & Single & 31 & $33.3 \%$ \\
\hline & Married & 41 & $44.1 \%$ \\
\hline & Separated & 10 & $10.8 \%$ \\
\hline & Windowed & 5 & $5.4 \%$ \\
\hline & Divorced & 6 & $6.5 \%$ \\
\hline \multirow[t]{4}{*}{ Level of education } & No formal education & 1 & $1.1 \%$ \\
\hline & Primary school & 18 & $19.4 \%$ \\
\hline & Secondary school & 54 & $58.1 \%$ \\
\hline & College/University & 20 & $21.5 \%$ \\
\hline \multirow[t]{5}{*}{ Monthly Income } & US\$ 1 to 500 & 34 & $36.6 \%$ \\
\hline & US\$ 501 to 1000 & 13 & $14.0 \%$ \\
\hline & US\$ 1,001 to 1,500 & 11 & $11.8 \%$ \\
\hline & US\$ 1,501 to 2,000 & 12 & $12.9 \%$ \\
\hline & Above US\$2,000 & 23 & $24.7 \%$ \\
\hline
\end{tabular}

Table 1: represent the bio-demographic data for age, gender, marital status, education level and monthly income 
International Journal of Advances in Scientific Research and Engineering (ijasre), Vol 7 (10), October -2021

\section{HAZARDOUS DRINKING}

Table 2: Hazardous drinking

\begin{tabular}{|c|c|c|c|}
\hline Item & st item & Frequency & Percentage \\
\hline \multirow[t]{5}{*}{ Sequence of alcohol consumption } & Never & 0 & $0.0 \%$ \\
\hline & Monthly or less & 2 & $2.2 \%$ \\
\hline & 2 to 4 times a month & 6 & $6.5 \%$ \\
\hline & 2 to 3 times a week & 19 & $20.4 \%$ \\
\hline & 4 or more times a week & 66 & $71.0 \%$ \\
\hline \multirow[t]{5}{*}{ Number of drinks in a typical day } & 1 to 2 & 2 & $2.2 \%$ \\
\hline & 3 to 4 & 11 & $11.8 \%$ \\
\hline & 5 to 6 & 13 & $14.0 \%$ \\
\hline & 7 to 9 & 16 & $17.2 \%$ \\
\hline & 10 or more & 51 & $54.8 \%$ \\
\hline Occasion consumed 5 or more & Never & 1 & $1.1 \%$ \\
\hline \multirow[t]{4}{*}{ drinks } & Less than monthly & 0 & $0.0 \%$ \\
\hline & Monthly & 5 & $5.4 \%$ \\
\hline & Weekly & 22 & $23.7 \%$ \\
\hline & Daily or almost daily & 65 & $69.9 \%$ \\
\hline
\end{tabular}

Table2: shows results for hazardous alcohol use domain

From the table 2 it indicates that the sequence of alcohol consumption was high at 4 or more times a week with a total respondents of 66(71.0\%) followed by 2 to 3 times a week with a total respondents of 19(20.4\%). With 0 respondents on never consumed alcohol and in a month or less indicated by 2 respondents out of a sample of 93 respondents. More than half percentage indicated by 10 or more number of drinks in a typical day with $54.8 \%$ respondents, while 7 to 9 with a total respondents of 16(17.2\%), for the case of 5 to 6,3 to 4 and 1 to 2 drinks in a typical day, were respondents of $14.0 \%, 11.8 \%$ and $2.2 \%$ respectively. The Daily or almost daily drinking recorded the highest score when assessing for 5 or more drinks in an occasion with $65(69.9 \%)$, the respondents who were assessed to drink weekly had an average of 22(23.7\%) of total respondents while $5.4 \%$ of respondents indicated that they drunk once in a month while none of the respondents drunk in less than a month.

\section{ALCOHOL DEPENDENCE}

To estimate the alcohol dependence was measured using the following parameters and the following results were achieved. Unable to stop drinking alcohol once started which was measured using the Likert scale where most of the respondents were found on daily or almost daily category with a total respondents of 48(51.6\%), a total of $18.3 \%$ indicated for the case of both weekly and monthly with a total of 17 respondents each. For the case of less than monthly had the lowest tally indicated by $4.3 \%$ and never was indicated by $7.5 \%$ of total respondents. To measure the alcohol dependency on unable to meet expectations due to drinking, most respondents were found in daily or almost daily with an average of $51.6 \%$ of total respondents. $26.9 \%$ (25) 
respondents indicated that weekly as their expectation to unable to meet expectations due to drinking with fewer respondents indicating for monthly, less than a monthly and never case with $9.7 \%, 8.6 \%$ and $3.2 \%$ respectively. For the need for first drink in the morning after a heavy drinking session most of respondents indicated by over half of the respondents with a total of $66.7 \%$, however weekly and monthly was indicated by $17.2 \%$ and $5.2 \%$ respectively similarly to less a monthly and never with $5.2 \%$ each. This is shown in the table 3 .

Table 3: Alcohol dependence

$$
\text { Less than }
$$

Daily or almost

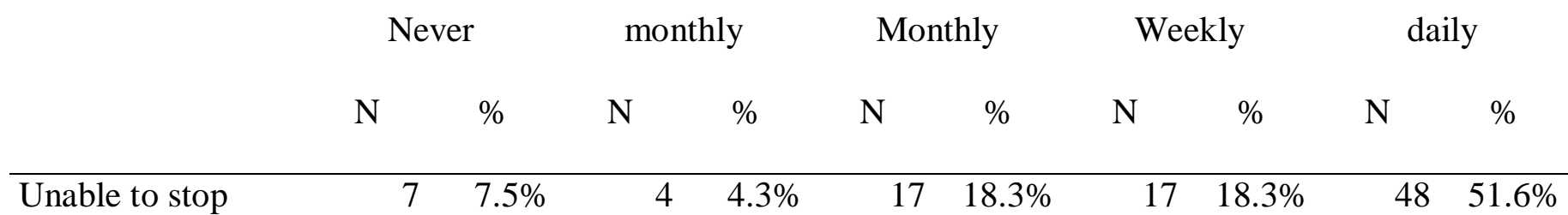

drinking alcohol

once started

Unable to meet

$3 \quad 3.2 \%$

$8 \quad 8.6 \%$

$9 \quad 9.7 \%$

$25 \quad 26.9 \%$

$48 \quad 51.6 \%$

expectations due to

drinking

Need for first drink

$5 \quad 5.4 \%$

$5 \quad 5.4 \%$

$5 \quad 5.4 \%$

$16 \quad 17.2 \%$

$62 \quad 66.7 \%$

in the morning

after a heavy

drinking session

\section{Table3: shows results for Dependence alcohol use domain}

\section{HARMFUL ALCOHOL USE}

To test for the harmful effects of alcohol use was tabulated in table 4. Most of the respondents indicated that daily or almost daily they felt about feeling remorseful after drinking with 50.5\%. Weekly, monthly, less than a month and never felt anything was indicated by $26.9 \%, 15.1 \%, 6.5 \%$ and $1.1 \%$ respectively. When assessing on the unable to remember events after night of drinking was measured by use of Likert scale were most of the respondents indicated that $51.6 \%$ almost daily or daily they were unable to remember events after night of drinking, $29.0 \%$ of respondents indicated that weekly they were unable to remember events after night of drinking, for cases of monthly, less than monthly and never, they were at $14.0 \%, 3.2 \%$ and $2.2 \%$ respectively. Most of respondents had injuries within the last year after having heavy drinking with a total percentage of $67.7 \%$ while $11.8 \%$ indicated that they didn't have any injury within the last year and $20.4 \%$ had no injury arising due to drinking alcohol. Concerns to cut down on drinking was presented where most of the respondents indicated that they were concerned to cut down on drinking over the last one year with $88.2 \%$ of total respondents while $11.8 \%$ the concerned to cut down on drinking but not in the last year. 
International Journal of Advances in Scientific Research and Engineering (ijasre), Vol 7 (10), October -2021

Table 4: Harmful alcohol use

Item Test item $\quad$ Frequency Percentage

\begin{tabular}{|c|c|c|c|}
\hline \multirow[t]{5}{*}{ Feeling remorseful after drinking } & Never & 1 & $1.1 \%$ \\
\hline & Less than monthly & 6 & $6.5 \%$ \\
\hline & Monthly & 14 & $15.1 \%$ \\
\hline & Weekly & 25 & $26.9 \%$ \\
\hline & Daily or almost daily & 47 & $50.5 \%$ \\
\hline Unable to remember events after & Never & 2 & $2.2 \%$ \\
\hline \multirow[t]{4}{*}{ night of drinking } & Less than monthly & 3 & $3.2 \%$ \\
\hline & Monthly & 13 & $14.0 \%$ \\
\hline & Weekly & 27 & $29.0 \%$ \\
\hline & Daily or almost daily & 48 & $51.6 \%$ \\
\hline Injury arising from drinking & No & 19 & $20.4 \%$ \\
\hline \multirow[t]{2}{*}{ alcohol } & Yes; but not in the last year & 11 & $11.8 \%$ \\
\hline & Yes; during the last year & 63 & $67.7 \%$ \\
\hline \multirow[t]{3}{*}{ Concerns to cut down on drinking } & No & 0 & $0.0 \%$ \\
\hline & Yes; but not in the last year & 11 & $11.8 \%$ \\
\hline & Yes; during the last year & 82 & $88.2 \%$ \\
\hline
\end{tabular}

Table4: shows results for the harmful alcohol use domain

\section{PAIRED T-TEST FOR ALCOHOL USE DISORDER IDENTIFICATION TEST (AUDIT) SCREENING TOOL}

There was significance between the audit tools since the significance was less than 0.05 for each pair under test. This was shown in table 5 
International Journal of Advances in Scientific Research and Engineering (ijasre), Vol 7 (10), October -2021

Table 5: Alcohol Use Disorder Identification Test (AUDIT) screening Tool

Paired Samples Correlations

\begin{tabular}{llr|r|r} 
& & N & Correlation & \multicolumn{1}{c}{ Sig. } \\
\hline Pair 1 & HT \& DT & 93 & .523 & .000 \\
\hline Pair 2 & HT \& HTT & 93 & .350 & .001 \\
\hline Pair 3 & DT \& HTT & 93 & .478 & .000
\end{tabular}

Paired samples t-tests; HT-Hazardous T-test, DT-Dependence T-test, HTT-Harmful T-test.

\subsection{Paired Samples Test}

Table 6: Paired Samples Test

Std. Std. Error

\begin{tabular}{lllcrrrrr} 
& & \multicolumn{1}{c}{ Mean } & Deviation & Mean & t & Df & \multicolumn{2}{c}{ Sig. (2-tailed) } \\
\hline Pair 1 & HT - DT & .80645 & 2.20798 & .22896 & 3.522 & 92 & .001 \\
Pair 2 & HT-HTT & -2.82796 & 2.68904 & .27884 & -10.142 & 92 & .000 \\
Pair 3 & DT - HTT & -3.63441 & 2.57406 & .26692 & -13.616 & 92 & .000
\end{tabular}

Table 6: shows correlation of the three domain of the AUDIT tool

From the table 6, it indicated that there was a no correlation between those individuals who had hazardous drinking and alcohol dependence with a t-value of 3.522 at $95 \%$ confidence interval which is less than table value 1.962 at $95 \%$ level of significance. For the hazardous drinking and harmful alcohol use had a positive correlation since t-value obtained was less than the table value at $95 \%$ confidence interval $(-10.142 \leq 3.522)$. The sample paired t-test between harmful alcohol use and alcohol dependence had a positive correlation $(-13.616 \leq 3.522)$ at 92 degree of freedom hence obtained t test value is being less than the table value.

\section{DISCUSSION}

The bio-demographic characteristic of the study showed more male participants than female. Majority of the participants were between the ages of 28 to 47 years. A study in morocco on participants between 15 and 18 years found that $94 \%$ were hazardous alcohol users ${ }^{18}$. Majority of the participants in our study were married with an annual income of U\$6000, similar to other findings in Thailand and Nepal where most of the responded with alcohol problem were of the married group ${ }^{15,19,20}$. Another study in USA found that $77 \%$ of the participants were married with an annual income of more than U\$150,000 ${ }^{21}$.

The study found skewness on gender with a high number of the participants being men. The findings were similar to those from a study in the same Country with high percentage of men than women found drinking alcohol ${ }^{22}$. The significant of this being that alcohol use disorder could be more in men than women from the Country.

More than half of the participants had education level equivalent to or above secondary school. Thus alcohol drinking was not influenced by low level of education. These results were compared to a study in Netherlands where university students had a high rate of hazardous alcohol use ${ }^{12}$. These results were contrary to the findings in Thailand where it was found that high education level influenced the consumption of alcohol, there were more harmful alcohol users with secondary and university education than those of the primary school levels ${ }^{23}$. A study showed that college persons had a 160 times more likely to consume alcohol, thus education level had influence on alcohol consumption ${ }^{24}$. 
Regarding the employment status, nearly half of the participants were employed while slightly more than half were unemployed. Thus employment status was not a major factor to influence the drinking pattern of the participants. There was no major difference on the employment status for participants in a different study from the same country ${ }^{22}$. There were similarities in drinking pattern for persons with low and high income. Therefore employment and income status were not the major contributing factors for alcohol consumption. Availability of cheap home brewed alcohol could be a factor that needed exploration. A study on alcohol done in USA, South Korea, Spain and Finland related hazardous alcohol use to increased access of alcohol products ${ }^{23}$. Another factor that may have influenced the outcome was little efforts put for early detection and treatment of alcohol use disorders ${ }^{26}$.

On hazardous alcohol use, the study found that more participants drink alcohol 4 or more times in a week. The number of drinks in a typical day was 10 or more for most of the participants while on the occasion the participants consumed 5 or more drinks, majority reported this as a daily or almost daily occurrence. A study in morocco found that $92 \%$ of the participants consumed 5 or more drinks every day of the week ${ }^{18}$. The test on dependence alcohol use found high percentages on daily or almost daily occurrence of unable to stop drinking alcohol once started, unable to meet expectations due to drinking and need for first drink in the morning after a heavy drinking session. Participants were unable to stop drinking probably because they were drinking from home or the take-away quantity was still available. The other parameters of unable to meet expectations and need for first drink could have been due to unable to stop consumption once started.

The test on harmful alcohol use found that near half of the participants experienced feelings of remorsefulness after drinking on daily or almost daily occasion. The results were compared with a study from Sau Luis where majority of the participants were not remorseful of drinking alcohol ${ }^{27}$.Nearly half of the participants reported unable to remember events after a night of drinking on daily or almost daily drink. The significant of this was that participants were likely to suffer from alcohol use disorder or other comorbidities and as such further diagnostic studies can improve the diagnostic evaluation ${ }^{22,28,29}$.

A high percentage of the participants reported concerns to cut down on drinking alcohol over the past one year. The findings show that the participants were not positively motivated by the behavior of drinking and this may have been the driving force for them to sort medical help at the rehabilitation centres. Drinking at home with the availability of family members may have triggers the concerns to cut down and sort medical advice. A study in India found that $20 \%$ of the participants with hazardous alcohol use had other comorbidities with majority providing a history of family experience in brewing alcohol at home ${ }^{30}$.

The cohort in our study was from the rehabilitation centres and this may be the reason for high percentages on hazardous, dependence and harmful alcohol use ${ }^{31}$. The finding of this study were consistent to a study in United States that reported increased alcohol use during the Covid-19 pandemic ${ }^{32}$. The Audit tool was enough to differentiate the at risk persons for hazardous alcohol use, dependence symptoms and harmful alcohol use for the respondents from rehabilitation centres ${ }^{29}$.

Majority of the respondents in the study reported high percentages on hazardous alcohol use, dependent symptoms and harmful alcohol use. These results were consistent with other studies which reported high alcohol use on the participants ${ }^{33,34}$. The results were inconsistent with the findings in a study in Nepal where a low percentage of participants had hazardous alcohol use, dependence symptoms and harmful alcohol use ${ }^{35}$. A study done in Kenya on a different cohort from a different County found low percentages of hazardous alcohol use, dependence use and harmful use ${ }^{36}$.

\section{CONCLUSION}

Age, education level or monthly incomes are not the major factors that influence alcohol consumption during the covid-19 pandemic. Hazardous alcohol use, alcohol dependence and harmful alcohol use can be helpful in categorization of alcohol use disorder during the Covid-19 pandemic. The pattern of alcohol drinking during the covid-19 pandemic can be evaluated by use of an alcohol use disorder identification test. Further research is needed to evaluate effects of alcohol on the body organs after long periodic alcohol consumption. This will aid in early detection on other comorbidities such as alcoholic liver injury.

Conflict of Interests: The authors declare no conflict of interest

Acknowledgements: The authors thank everyone who contributed to the achievement of this study.

Availability of data material: The data material in this study is available upon request from the authors. 


\section{REFERENCES}

1. Higgins-Biddle, J. C., \& Babor, T. F. (2018). A review of the Alcohol Use Disorders Identification Test (AUDIT), AUDIT-C, and USAUDIT for screening in the United States: Past issues and future directions. The American journal of drug and alcohol abuse, 44(6), 578-586.

2. Manthey, J., Shield, K. D., Rylett, M., Hasan, O. S., Probst, C., \& Rehm, J. (2019). Global alcohol exposure between 1990 and 2017 and forecasts until 2030: a modelling study. The Lancet, 393(10190), 2493-2502.

3. Lim, S. S., Allen, K., Bhutta, Z. A., Dandona, L., Forouzanfar, M. H., Fullman, N., ... \& Chang, J. C. (2016). Measuring the health-related Sustainable Development Goals in 188 countries: a baseline analysis from the Global Burden of Disease Study 2015. The Lancet, 388(10053), 1813-1850.

4. World Health Organization. (2013). Global action plan for the prevention and control of noncommunicable diseases 2013-2020. World Health Organization.

5. World Health Organization. (2019). Global status report on alcohol and health 2018. World Health Organization 16-17. Retrieved from https://apps.who.int/iris/bitstream/handle/10665/274603/9789241565639-eng.pdf

6. Zewdu, S., Hanlon, C., Fekadu, A., Medhin, G., \& Teferra, S. (2019). Treatment gap, help-seeking, stigma and magnitude of alcohol use disorder in rural Ethiopia. Substance abuse treatment, prevention, and policy, 14(1), 1-10.

7. Nalwadda, O., Rathod, S. D., Nakku, J., Lund, C., Prince, M., \& Kigozi, F. (2018). Alcohol use in a rural district in Uganda: findings from community-based and facility-based cross-sectional studies. International journal of mental health systems, 12(1), 1.

8. Rehm, J., Neufeld, M., Yurasova, E., Bunova, A., Gil, A., Gornyi, B., ... \& Ferreira-Borges, C. (2020). Adaptation of and protocol for the validation of the alcohol use disorders identification test (audit) in the russian federation for use in primary healthcare. Alcohol and Alcoholism, 55(6), 624-630.

9. Babor, T. F., Higgins-Biddle, J. C., Saunders, J. B., \& Monteiro, M. G. (2001). The alcohol use disorders identification test: Guidelines for use in. World Health Organization. Recuperado de https://apps. who. int/iris/handle/10665/67205.

10. Moehring, A., Krause, K., Guertler, D., Bischof, G., Hapke, U., Freyer-Adam, J., ... \& Meyer, C. (2018). Measurement invariance of the alcohol use disorders identification test: Establishing its factor structure in different settings and across gender. Drug and alcohol dependence, 189, 55-61.

11. Nadkarni, A., Garber, A., Costa, S., Wood, S., Kumar, S., MacKinnon, N., ... \& Rane, A. (2019). Auditing the AUDIT: A systematic review of cut-off scores for the Alcohol Use Disorders Identification Test (AUDIT) in low-and middleincome countries. Drug and alcohol dependence, 202, 129.

12. Verhoog, S., Dopmeijer, J. M., de Jonge, J. M., van der Heijde, C. M., Vonk, P., Bovens, R. H., ... \& Kuipers, M. A. (2020). The use of the alcohol use disorders identification test-consumption as an indicator of hazardous alcohol use among university students. European addiction research, 26(1), 1-9.

13. Gowin, J. L., Sloan, M. E., Stangl, B. L., Vatsalya, V., \& Ramchandani, V. A. (2017). Vulnerability for alcohol use disorder and rate of alcohol consumption. American Journal of Psychiatry, 174(11), 1094-1101.

14. Kawaida, K., Yoshimoto, H., Saito, G., \& Takayashiki, A. (2021). Optimal Cutoff Values of the Alcohol Use Disorders Identification Test and its Short Version for Detecting Excessive Alcohol Use in Japanese College Students. The Tohoku Journal of Experimental Medicine, 253(1), 3-10.

15. Eashwar, V. A., Gopalakrishnan, S., Umadevi, R., \& Geetha, A. (2019). Pattern of alcohol consumption and its associated morbidity among alcohol consumers in an urban area of Tamil Nadu. Journal of family medicine and primary care, 8(6), 2029

16. Demilew, D., Tesfaw, G., Kerebih, H., \& Salelew, E. (2020). Alcohol Use Disorder and Associated Factors Among Medicaland Surgical Outpatients of University of Gondar Specialized Hospital: A Cross-sectional Study.

17. Harper, G. W., Crawford, J., Lewis, K., Mwochi, C. R., Johnson, G., Okoth, C., ... \& Wilson, B. D. (2021). Mental health challenges and needs among sexual and gender minority people in western Kenya. International journal of environmental research and public health, 18(3), 1311.

18. Ben El Jilali, L., Benazzouz, B., El Hessni, A., Ouichou, A., \& Mesfioui, A. (2020). Prevalence of alcohol consumption and alcohol use disorders among middle and high school students in the province of Khemisset, Morocco: a crosssectional study. International Journal of Adolescence and Youth, 25(1), 638-648.

19. Assanangkornchai, S., Nontarak, J., Aekplakorn, W., Chariyalertsak, S., Kessomboon, P., \& Taneepanichskul, S. (2020). Socio-economic inequalities in the association between alcohol use disorder and depressive disorder among Thai adults: a population-based study. BMC psychiatry, 20(1), 1-11.

20. Rathod, S. D., Luitel, N. P., \& Jordans, M. J. D. (2018). Prevalence and correlates of alcohol use in a central Nepal district: secondary analysis of a population-based cross-sectional study. Global Mental Health, 5.

21. Boschuetz, N., Cheng, S., Mei, L., \& Loy, V. M. (2020). Changes in alcohol use patterns in the United States during COVID-19 pandemic. Wmj, 119(3), 171-176. 
22. Jenkins, R., Othieno, C., Ongeri, L., Kiima, D., Sifuna, P., Kingora, J., ... \& Ogutu, B. (2015). Alcohol consumption and hazardous drinking in western Kenya - a household survey in a health and demographic surveillance site. BMC psychiatry, 15(1), 1-10.

23. Savolainen, I., Oksanen, A., Kaakinen, M., Sirola, A., Miller, B. L., Paek, H. J., \& Zych, I. (2020). The Association between social media use and hazardous alcohol use among youths: A four-country study. Alcohol and alcoholism, 55(1), 86-95.

24. Assanangkornchai, S., Nontarak, J., Aekplakorn, W., Chariyalertsak, S., Kessomboon, P., \& Taneepanichskul, S. (2020). Socio-economic inequalities in the association between alcohol use disorder and depressive disorder among Thai adults: a population-based study. BMC psychiatry, 20(1), 6-9.

25. Lui, P. P., Berkley, S. R., \& Zamboanga, B. L. (2020). College alcohol belief and alcohol use: Testing moderations by cultural orientations and ethnicity. Journal of counseling psychology, 67(2), 13

26. Dowhaniuk, N., Ojok, S., \& McKune, S. L. (2021). Setting a research agenda to improve community health: An inclusive mixed-methods approach in Northern Uganda. Plos one, 16(1), e0244249.Retrieved https://journals.plos.org/plosone/article?id=10.1371/journal.pone.0244249.

27. Machado, P. M. A., Campelo, C. L., Oliveira, J. V. P. D., Batista, R. F. L., Simões, V. M. F., \& Santos, A. M. D. (2021). Analysis of the AUDIT factor structure in adolescents between 18 and 19 years. Revista de saude publica, 55. Retrieved https://www.scielo.br/j/rsp/a/mXMx6Z4qi3fM64TWH9x7jQm/?lang=en\&format=pdf.

28. Haile, Y. G., Kebede, K. B., Limenhe, A., Habatmu, K., \& Alem, A. (2020). Alcohol use disorder among prisoners in Debre Berhan prison, Ethiopia: a cross-sectional study. Substance abuse treatment, prevention, and policy, 15, 1-11.

29. Villarosa-Hurlocker, M. C., Schutts, J. W., Madson, M. B., Jordan, H. R., Whitley, R. B., \& Mohn, R. C. (2020). Screening for alcohol use disorders in college student drinkers with the AUDIT and the USAUDIT: a receiver operating characteristic curve analysis. The American journal of drug and alcohol abuse, 46(5), 531-545.

30. Thummar, P. D., \& Rupani, M. P. (2020). Prevalence and predictors of hazardous alcohol use among tuberculosis patients: The need for a policy on joint tuberculosis-alcohol collaborative activities in India. Alcohol, 86, 113-119

31. Verenkar, Y. J., \& Vaz, F. S. (2018). Prevalence and pattern of alcohol consumption using alcohol use disorder identification test among students at a medicalcollege in Goa, India. Int J Community Med Public Health, 5(7), 29352938. Reported that $46.7 \%$ of the participants were hazardous alcohol consumers.

32. Killgore, W. D., Cloonan, S. A., Taylor, E. C., Lucas, D. A., \& Dailey, N. S. (2021). Alcohol dependence during COVID-19 lockdowns. Psychiatry research, 296, 113676.

33. Niclasen, B., Flyger, J., Becker, U., Nielsen, B., \& Nielsen, A. S. (2021). Implementation of AUDIT in the treatment planning process for alcohol use disorder in Greenland. Nordic Journal of Psychiatry, 75(2), 145-151.

34. Blair, A. H., Pearce, M. E., Katamba, A., Malamba, S. S., Muyinda, H., Schechter, M. T., \& Spittal, P. M. (2017). The alcohol use disorders identification test (AUDIT): exploring the factor structure and cutoff thresholds in a representative post-conflict population in northern Uganda. Alcohol and Alcoholism, 52(3), 318-327.

35. Rathod, S. D., Luitel, N. P., \& Jordans, M. J. D. (2018). Prevalence and correlates of alcohol use in a central Nepal district: secondary analysis of a population-based cross-sectional study. Global Mental Health, 5.

36. Long, J. E., Richardson, B. A., Wanje, G., Wilson, K. S., Shafi, J., Mandaliya, K., ... \& McClelland, R. S. (2020). Alcohol use and viral suppression in HIV-positive Kenyan female sex workers on antiretroviral therapy. PloS one, 15(11), e0242817.

- Corresponding Author: George Njoroge: gnjoroge@mku.ac.ke 